\title{
Etiopatogênese da infecção por parvovírus humano B19 e relação com leucemias agudas da infância
}

\author{
Human parvovirus B19: etiopathogenesis and relation with leukaemias
}

\author{
William Augusto Casteleins Cećlio', Maria do Socorro Pombo de Oliveira²
}

\section{Resumo}

O parvovírus humano B19 (B19V) é o agente causador do eritema infeccioso em crianças, há muito conhecido como "quinta doença". Esta infecção foi descrita inicialmente há mais de 100 anos, no entanto há apenas 30 anos 0 vírus tornou-se conhecido dos cientistas. Apesar de se resolver sem maiores complicações, em indivíduos normais (imunocompetentes), alguns grupos de pacientes merecem especial atenção quando acometidos por este parvovírus, tendo em vista as sérias complicações que podem vir a apresentar no futuro. Entre tais pacientes encontram-se os portadores de hemoglobinopatias, imunocomprometidos e fetos. Especula-se que a infecção por B19 está associada a etiopatogênese de leucemias agudas. Atualmente, modernas técnicas vêm sendo empregadas para o diagnóstico desta doença, incluindo a dosagem sérica de imunoglobulinas e a detecção do vírus. 0 tratamento, por outro lado, continua sintomático na maior parte dos casos. $\mathrm{N}$ o entanto novas abordagens terapêuticas com uso anti-retroviral vêm sendo utilizadas, especialmente nas complicações que o parvovírus provoca. 0 objetivo deste trabalho é apresentar uma revisão enfocando os principais aspectos clínicos, imunocelulares e terapêuticos desta doença exantemática comumente subestimada.

Palavras-chave: Parvovírus B19 humano; Vírus B19; Eritema infeccioso; Leucemia Aguda; Criança.

\begin{abstract}
The human parvovirus B19 (B19V) is the causing agent of the erythema infectiosum in children known, for a long time as "fifth disease". This infection albeit initially described over 100 years ago, only in the past 30 years the virus became known by the scientists. In spite of resolving with no serious complications, in immunocompetent individuals, different groups of patients deserve special attention when infected by this parvovirus, due to the severe outcomes that may occur. Among such patients are the carriers of hemoglobinopathies, immunocompromised individuals, and fetus. It is speculated that the B19V infection is related to the pathogenesis of acute leukaemias. N owadays, modern techniques have been applied for the diagnosis of this illness, including the detection of the virus and immunoglobulin dosage in the serum. The treatment, on the other hand, remains symptomatic in the majority of the cases. H owever, new anti-retroviral therapeutic approaches have been used, specially when complications are manifested. The purpose of this study is to present a review focusing on the main clinical, immunocellular and therapeutical aspects of this commonly underestimated exanthematic disease.
\end{abstract}

Key words. H uman parvovirus B19; B19 virus; Erythema infectiosum; Acute leukemia; Child.

\footnotetext{
${ }^{1}$ Acadêmico de M edicina, 50 Período, PU CPR - Bolsista CN Pq do Programa Aristides Pacheco Leão de Estímulo a Vocações Científicas de 2004 , da Academia Brasileira de Ciências.

${ }^{2}$ M édica PhD, pesquisadora do Instituto N acional de Câncer , Coordenadoria de Pesquisa, Divisão de M edicina Experimental - Grupo de Pesquisa sobre Patogênese das Leucemias/Linfomas. Instituto Nacional de Câncer.

Endereço para correspondência: M.S.P.O - Instituto Nacional de Câncer, Coordenação de Pesquisa - IN CA - Rua André Cavalcante, 37. Centro. CEP: 20231-050. Rio de Janeiro - RJ - Brasil. E-mail: mspombo@inca.gov.br

Patrocinador: Bolsa concedida pelo CN Pq por meio do Programa Aristides Pacheco Leão de Estímulo a Vocações Científicas, da Academia Brasileira de Ciências.
} 


\section{INTRODUÇÃO}

0 interesse em fazer esta revisão surgiu ao analisarmos ao microscópio óptico um esfregaço sanguíneo suspeito de leucemia, em laboratório da D ivisão de M edicina Experimental do Instituto $\mathrm{N}$ acional de Câncer (INCA). A amostra da criança estudada apresentava uma alteração importante nas séries eritróide e linfóide, o que despertou a atenção para uma possível infecção parvoviral. Após análise por imunofenotipagem, descartou-se a hipótese de leucemia. Este resultado e a evolução clínica da criança, corroboraram com o diagnóstico diferencial de possível reação linfóide e eritropoética à infeção viral. Estudos complementares através de análise sorológica estão em curso.

$\mathrm{N}$ osso interesse neste assunto se justifica pela possível associação de agentes infecciosos nos estudos de etiopatogênese das leucemias. Em 1988, Kinlen ${ }^{1}$, sugere que residentes em regiões de alta mistura populacional estariam sujeitos a um risco aumentado de desenvolver leucemias. Sua hipótese se baseia na observação de que em áreas previamente isoladas no Reino Unido, as quais receberam um grande afluxo populacional nos anos 1950, foram constatados níveis de ocorrência de leucemia mais altos que a média nacional para a época. U ma das explicações postuladas para este fato seria o aumento na exposição destes habitantes a infecções virais para as quais possuíam uma baixa imunidadenatural. Estes agentes infecciosos seriam os responsáveis pelo desencadeamento de leucemias agudas. Suspeita-se atualmente dos seguintes agentes: Epstein-Barr virus, herpes virus tipo 6 e o parvovírus $B 19^{2}$. D esde então vários pesquisadores têm procurado, através de estudos imunomoleculares, estabelecer associação entre agentes infeciosos e leucemias infantis.

Greaves ${ }^{3}$, em um artigo de revisão, cita duas hipóteses sugerindo que uma resposta anormal a infecções comuns tem um papel decisivo no desenvolvimento de leucemia linfóide aguda na infância. A primeira baseia-se nas conclusões de Kinlen (1988), já citadas, em que aumentos nos níveis de leucemia, em certos agrupamentos populacionais, devem-se à mobilidade e mistura populacional resultando em infecções ocorrendo em indivíduos previamente não expostos ou susceptíveis. A segunda, denominada por G reaves de hipótese da "infecção atrasada", afirma que leucemia linfóide aguda é causada por uma falta de exposição a infecção e por uma falha no sistema imune infantil. N estas crianças, posteriormente, uma resposta imune anormal ocorre a infecções bacterianas e virais comuns, que acontecem tardiamente (atrasadas).

Em 1995, Kinlen e Petridou4, estudando índices de mortalidade infantil devido a leucemia em 33 países, ocorridas durante os anos de 1950 e 1960, perceberam aumentos significativos nestes índices em áreas rurais sujeitas a migrações e misturas populacionais. 0 s autores destacam o cuidado por eles tomado ao fazer comparações internacionais quanto à mortalidade e percebem que, dentro deste contexto, G récia e Itália se sobressaem, corroborando a hipótese das infecções proposta por Kinlen em 1988.

\section{ETIOLOGIA}

O parvovírus B19 (B19V) é membro da família Parvoviridae, tendo seu material genético constituído por uma fita simples de DNA e apresentando um tropismo por células progenitoras eritróides da medula óssea (incluíndo unidades formadoras de colônia) e do sangue, onde se replica, inibindo a eritropoese e causando efeitos citotóxicos. A infecção começa quando - capsídeo se une aos antígenos P (um glicoesfingolipídeo) da linhagem vermelha (especialmente os proeritroblastos), aproveitando-se destas células em ativa divisão para replicar-se. ${ }^{5,6,7,8}$

É 0 agente etiológico do eritema infeccioso, freqüentemente observado em crianças e cujas manifestações clínicas mais comuns são a eritrodermia (rash cutâneo) e febre. ${ }^{5}$ Este exantema infantil benigno foi inicialmente descrito em 1889, e então denominado "quinta doença", devido à sua posição na classificação numérica dos exantemas infantis (antecedido por sarampo, escarlatina, rubéola e doença de Dukes - a qual não é mais considerada uma doença em separado). ${ }^{7}$ N o entanto, somente em 1974 teve sua estrutura genética elucidada por Cossart et al. ${ }^{6,9}$, após ter sido descoberto por acidente em pesquisa de vírus da hepatite B em doadores de sangue. M ais tarde, em 1983, foi feita definitivamente a associação entre 0 parvovirus B19 e o eritema infeccioso, por Anderson et al.6, 9

O B19V não possui um envelopelipídico, não sendo, portanto, eliminado pelas técnicas de inativação viral baseadas em solventes e detergentes normalmente aplicados aos hemoderivados industrializados. Isto implica numa fonte de transmissão sangüínea iatrogênica. A prevalência deste vírus em doadores de sangue varia de 1 caso para cada 20.000 a 40.000 doações. A taxa de transmissão deste vírus através das transfusões não é conhecida. ${ }^{5}$

\section{EPIDEMIOLOGIA DA INFECÇÃO POR BI9V}

0 eritema infeccioso tem uma distribuição mundial, com epidemias escolares ocorrendo ao final do inverno e começo da primavera. Afeta primeiramente crianças entre 4 e 10 anos. ${ }^{6}$ Adultos, por outro lado, também são afetados, mas apresentando manifestações clínicas 
diferentes das crianças. ${ }^{6,7,9}$

0 corrência sazonal, com epidemias espalhadas por toda uma comunidade ocorrem em muitas áreas a cada 3-5 anos. Estudos sorológicos limitados, disponíveis em 1992 e produzidos na Inglaterra, França, C anadá, Japão, Estados U nidos e Alemanha O riental, indicam que a prevalência de IgG para B19V numa população aumenta com a idade. Estes estudos encontraram positividade para esta IgG entre 2 e $9 \%$ das crianças com menos de 5 anos, entre 15 e $35 \%$ dos jovens entre 5 e 18 anos e entre 30 a $60 \%$ dos adultos com mais de 19 anos. ${ }^{6}$

Relatos epidemiológicos destas infecções são escassos no Brasil. Alguns estudos mostraram que as infecções estão amplamente espalhadas em alguns estados brasileiros. O liveira et al. ${ }^{9}$ conduziram um estudo clínico e epidemiológico por 6 anos, entre Janeiro de 1994 e D ezembro de 1999, no M unicípio de N iterói, RJ, quando 673 pacientes com doenças exantemáticas agudas foram atendidos por unidades primárias de saúde e pelo H ospital U niversitário Antônio Pedro. Q uarenta e nove por cento (330 casos) foram encontrados sorologicamente negativos (I gM) para dengue, rubéola e sarampo ou com baixa avidez (IgG) para H H V-6 (herpes vírus humano tipo 6). D estes, 105 (31,8\%) foram identificados I gM positivos (infecção ativa) para B19V. A distribuição de casos através dos anos mostrou clara variação sazonal (Julho a D ezembro), com picos nos anos de 1994, 1998 e 1999. A maioria dos casos ocorreu em crianças $(69,5 \%)$ com igual prevalência entre meninos e meninas. Já em adultos houve predominância em mulheres $(81,3 \%)$. O s outros 343 casos desta pesquisa correspondem a todos os outros exantemas humanos.

\section{Patogênese, diagnóstico e tratamento da infecção PARVOVIRAL}

A transmissão do B19V ocorre por perdigotos, cuja porta de entrada e via de eliminação é o sistema respiratório. 0 período de incubação, até o surgimento do exantema, é de 4 a 15 dias. 0 casionalmente alguns sintomas antecipam a erupção cutânea: febre baixa, faringite, cefaléia, mialgias, náusea, diarréia e dores articulares (poliartrite). Em indivíduos com anemia hemolítica crônica ou com AIDS pode provocar o aparecimento de crise aplástica. 0 período de transmissão vai de 7 dias antes da erupção até o primeiro dia do exantema em indivíduos normais. No entanto, pacientes com crise aplástica tornam-se potencialmente contagiosos por uma semana ou mais após o surgimento do exantema. 6.7

0 eritema infeccioso caracteriza-se por placas exantemáticas e edematosas nas bochechas, atingindo também as asas nasais e a região periorbital. Isto tende a desaparecer entre 1 e 4 dias. 0 exantema se espalha para o tronco e extremidades, podendo tornar-se pruriginoso. Esta erupção dura de 5 a 9 dias, mas pode tornar-se recorrente por semanas a meses, sendo desencadeada pela luz solar, exercícios, mudanças de temperatura, banho e estresse emocional. ${ }^{7}$

Um enantema pode estar presente, consistindo de eritema de língua e faringe, freqüentemente com máculas na mucosa oral e palatina. Artralgia e artrite são percebidas em $10 \%$ das crianças afetadas, tipicamente envolvendo grandes articulações por um breve espaço de tempo. ${ }^{7}$

Em adultos, a primeira infecção resulta em sintomas mais severos. Febre, adenopatia e artrite, particularmente em mulheres, sem erupção cutânea, correspondem ao curso usual da doença. Se o exantema estiver presente em adultos, irá se apresentar geralmente como máculas, começando nas extremidades e progredindo caudalmente. ${ }^{7}$ Foi descrita também a ocorrência de alguns casos de encefalite, abdome agudo não-cirúrgico e síndrome hemofagocítica. ${ }^{8}$

$\mathrm{N}$ as infecções pelo B19V, severos danos podem ocorrer em 3 grupos de patientes: imunocomprometidos, fetos e pacientes com hemoglobinopatias.

Em pacientes com anemia hemolítica crônica, uma crise aplástica transitória, manifestada por anemia, reticulocitopenia e aplasia eritrocitária, pode ocorrer. $\mathrm{N}$ a verdade todas as séries hematopoéticas podem estar afetadas, provocando também diferentes níveis de neutropenia e trombocitopenia. Apesar de ser transitória, a crise pode deixar os pacientes extremamente debilitados e até matá-los. Crise aplástica pode ocorrer também em pacientes com esferocitose hereditária, deficiência da enzima G 6PD (glicose-6-fosfatodesidrogenase), deficiência de piruvato-quinase, deficiência de ferro e portadores de talassemias, que venham a ser infectados por este vírus. A aplasia é autolimitada e responde bem às transfusões, ${ }^{6,7,8}$

D evido ao fato de pacientes com crises aplásticas serem contagiosos por um longo período de tempo e pacientes imunocomprometidos poderem sofrer infecção parvoviral crônica, precauções contra perdigotos são recomendadas no cuidado a estes pacientes. Alguns pacientes podem ter somente uma aplasia transitória ou uma crise eritrocitária e nestes casos a proteção contra perdigotos dever ser continuada por 7 dias. $^{7}$

Em pacientes imunocomprometidos, como aqueles com H IV, imunodeficiências congênitas, leucemias agudas, transplantados, portadores de lúpus eritematoso ou em lactentes com menos de 1 ano, o parvovírus B19 pode causar uma séria e prolongada anemia crônica, 
devido à lise contínua dos precursores eritróides. ${ }^{7} \mathrm{Um}$ estudo conduzido em unidades pediátricas de hematologia-oncologia da Grécia, em 2001, mostrou que entre crianças com 5 anos ou mais, o risco de leucemia linfocítica aguda (LLA) pode ser elevado quando a baixa imunidade destas crianças é desafiada por infecção por agentes infecciosos comuns na infância, entre os quais o B19V, que seriam os responsáveis por desencadear esta LLA. ${ }^{10}$

Em novembro de 2003, Kerr et al. ${ }^{11}$ investigaram a associação entre infecção aguda pelo B19V e início de leucemia linfoblástica(LLA) emiolocítica (LM A) agudas. Para tanto coletaram amostra de líquido cefalorraquidiano de 14 pacientes com LLA e 2 pacientes com LM A e analisaram por PCR para detecção do D N A viral. D estes, 4 casos foram positivos para B19V, 3 deles de LLA e 1 de LM A M 7. Todos os pacientes estavam significantemente anêmicos, mas nenhum apresentava encefalite ou tinha evidências de invasão leucêmica no sistema nervoso central. Três destes pacientes tinham níveis sorológicos detectáveis de fator de necrose tumoral alfa (TNF-a), interferon gama (IFN-g), interleucina 6 (IL-6), fator estimulante de colônia de granulócitos e macrófagos (CSF-GM) e proteína quimiotática de macrófagos. Todos os 4 pacientes eram portadores de pelo menos 1 alelo HLA-DRB1, o qual foi associado com infecção sintomática do B19V. O s autores concluíram que tanto supressão da linhagem eritróide quanto proliferação celular imune estão associados a infecção pelo parvovírus e podem também ser importantes na patogênese de leucemias agudas.

Especial atenção deve ser dada durante a gravidez, pois infecções pelo B19V podem resultar em transmissão vertical para o feto, causando infecção dos precursores eritróides e hemólise intensa, levando a severa anemia, hipóxia tecidual, insuficiência cardíaca e edema generalizado (compatível com hydrops fetalis) levando à morte do feto. A maioria dos danos secundários a este vírus ocorrem no primeiro trimestre de gravidez. Imunidade é conferida após infecção e $50 \%$ das mulheres em idade fértil são soropositivas (IgG) com ausência de IgM, indicando infecção anterior. A taxa de transmissão vertical, em lactentes expostos a mães infectadas durante a gestação (confirmada pela positividade de IgG nestas crianças) é relatada em 16\% se expostas durante as primeiras 20 semanas e $35 \%$ depois das 20 semanas de gestação. ${ }^{8} \mathrm{~N} 0$ entanto, se houver diminuição na resposta imune anti-viral da mãe, a susceptibilidade fetal a infecção por este vírus pode ser aumentada. ${ }^{12} 0$ risco de desenvolver hidropsia fetal por anemia hemolítica é $10 \%$ e esta taxa decresce conforme avança a gravidez. ${ }^{7} \mathrm{~N}$ os recém-natos que sobrevivem à hidropsia fetal, a maioria se recupera sem seqüelas, no entanto alguns podem desenvolver anemia crônica. ${ }^{8}$ Existe também a possibilidade do diagnóstico pré-natal da infecção ser realizado, por meio de amostras coletadas do sangue fetal ou do líquido amniótico. ${ }^{13}$

0 método diagnóstico mais moderno e sensível disponível atualmente é a identificação do D N A viral na medula óssea ou no sangue periférico usando PCRELISA (polymerase chain reaction - enzyme-linked immunosorbent assay) e técnicas de hibridização, muito embora anticorpos I gM sejam detectados após o terceiro dia e o pico esteja na segunda semana após a infecção. D este modo, o protocolo para diagnóstico laboratorial mais apropriado consta de PCR-ELISA para determinar a presença do D N A viral juntamente com I gM específica para o B19V., ${ }^{8,14}$ Começa a haver declínio de IgM após 30-60 dias dos sintomas e geralmente não é mais encontrado em 60-90 dias. Anticorpos IgG aparecem após I gM e permanecem pelo resto da vida do paciente, sendo, por essa razão, úteis como marcadores de infecção passada e de imunidade. 0 teste demonstrará infecção primária ativa pelo B19V quando IgM for positiva, no entanto para uma re-infecção, ele pode ser impreciso. ${ }^{3} \mathrm{~A}$ amplificação do DN A viral torna-se mais difícil em amostras de soro, porque a viremia costuma durar somente 2 ou 3 dias. $^{8}$ Pacientes imunocomprometidos, não obstante, podem persistir em viremia por mais tempo. Exames microscópicos da medula óssea podem ser úteis. $N$ estes, a presença de pronormoblastos gigantes numa medula hipoplástica sugere infecção por B19V. A partícula viral pode ser visualizada apenas em microscópio eletrônico. 0 vírus nunca foi detectado em fezes, mas foi em amostras de urina. $^{6}$

Foi demonstrada também a existência de anticorpos IgE anti-parvovirus e a possibilidade de sua detecção para diagnóstico desta virose. Para isto foram estudadas as características imunológicas de um paciente masculino de 8 anos nos dias 0, 14 e 210 após a apresentação dos sintomas. Este paciente tinha sido submetido anteriormente a vários testes para alergenos e, portanto, conhecia-se o seu valor sérico de IgE (150 $\mathrm{IU} / \mathrm{mL})$. Q uando confirmou-se o diagnóstico de infecção por B19V, os níveis séricos de IgE haviam aumentado para $256 \mathrm{IU} / \mathrm{mL}$ no dia $0,233 \mathrm{IU} / \mathrm{mL}$ no dia 14 e retornaram aos níveis de préinfecção no dia 210. Além disso, níveis de proteína IgE anti-B19V foram detectados no soro por meio de Western blot nos dias 0,14 e 210, apesar do decréscimo de IgE total no dia 210. Isto sugere que tais anticorpos (IgE anti-B19V) podem ser úteis para determinação de prognóstico em infecções por B19V. Os autores também defendem a 
idéia de que IgE, de um modo geral, tem um papel fundamental na imunidade anti-viral, talvez em conjunto com células B CD 23+. ${ }^{15}$

O tratamento da infecção pelo B19V ainda é, na maior parte das vezes, sintomático. Pacientes com anemias hemolíticas que desenvolvem crise aplástica transitória precisam ser tratados dos sintomas da anemia e podem necessitar de transfusão sangüínea. G estantes com sinais ou sintomas sugestivos de infecção pelo B19V, ou exposição a pessoas infectadas, devem ser testadas sorologicamente para IgM e IgG. Se existe infecção materna, com níveis de IgM positivos, então ultrasonografias periódicas devem ser realizadas no feto para avaliar alterações compatíveis com hidropsia fetal. Tais pacientes devem ser encaminhados para centros terciários de saúde a fim de se submeterem a cordocentese e a uma possível transfusão sangüínea fetal, se houver indicação. ${ }^{7}$ D a mesma maneira, crianças que foram diagnosticadas com anemia aplástica devem ser testadas para infecção por B19V, porque as duas doenças estão associadas e há possi bilidade desta infecção ocorrer de maneira assintomática em crianças. ${ }^{16}$ Além disso, deve-se considerar e testar para infecções por esse vírus crianças apresentando pancitopenia de origem desconhecida, pois quadros semelhantes a síndrome mielodisplástica já foram atribuídos a ele em crianças com deficiência subclínica de IgM.${ }^{17}$

$\mathrm{Em}$ relação à resposta imune contra o $\mathrm{B} 19 \mathrm{~V}$ em humanos, a formação de anticorpo antiviral específico é considerado o principal mecanismo de proteção (correspondendo clinicamente ao aparecimento do exantema cutâneo). Isto se baseia em evidências circunstanciais de que altas doses de terapia imunoglobulínica (imunoglobulina intravenosa) às vezes é benéfico para pacientes infectados. Este tratamento não funciona em todos os casos; ele está indicado para crianças com infecção crônica e que continuam dependentes de transfusões após o fim da quimioterapia para tratamento decâncer. N ão há informação disponível sobre a real proteção da IgG B19V, apesar de níveis maiores que 6 IU serem considerados protetores. ${ }^{6,8,18}$

Em 2001 foi feita a primeira descrição na literatura do caso de um homem de 22 anos previamente saudável que sofreu severa anemia aplástica e pancitopenia, em que foram encontrados elevados níveis de anticorpos IgM e IgG específicos para B19V e Epstein-Barr vírus (EBV) simultaneamente, além de ter detectados por PCR os genomas de ambos os vírus nas células nucleadas da medula óssea e nos linfócitos do sangue periférico. 0 tratamento foi realizado com prednisona, acyclovir e imunoglobulina intravenosa, porém após 2 meses ainda havia necessidade de transfusões de suspensão de plaquetas e de concentrado de hemáceas. Este paciente foi submetido a transplante alogênico de medula óssea e por 8 meses apresentou uma dificultada resposta hematológica completa. ${ }^{19}$

Em 1992 foi publicado na literatura um caso de envolvimento renal no contexto de uma infecção severa pelo B19V. O paciente desenvolveu um quadro de insuficiência renal aguda, cujo resultado foi favorável após tratamento sintomático e diálise temporária. $0 \mathrm{~s}$ autores presumem que o mecanismo de falha renal neste caso foi multifatorial. ${ }^{20}$ Como se pode observar, o B19V se relaciona a um vasto espectro de doenças. ${ }^{21}$

Recentemente, em N ovembro de 2003, teve início a fase I dos testes clínicos de uma vacina contra o B19V, patrocinado pela $\mathrm{N}$ ational $\mathrm{H}$ eart, Lung, and Blood Institute (N H LBI) N orte-Americana. Esta vacina será composta de capsídeos recombinantes do parvovirus B19, patenteados pelo governo federal dos EUA. A fase I irá durar 9 meses, a partir da qual poderá ou não avançar para a fase II de testes. ${ }^{22} \mathrm{~N} 0$ entanto ainda não existe uma vacina aprovada contra o B19V, mas se vier a existir, os candidatos a vacinação serão principalmente os pacientes com supressão crônica da medula óssea. ${ }^{6}$

\section{AGRADECIMENTOS}

a) Dr. M arcello André Barcinski, médico PhD, chefe da D ivisão de M edicina Experimental do INCA e membro da Academia Brasileira de Ciências.

b) Programa Aristides Pacheco Leão de Estímulo a Vocações Científicas da Academia Brasileira de Ciências, por proporcionar oportunidade de estágio em laboratórios do IN CA e por fornecer auxílio financeiro do CNPq (Conselho Nacional de Pesquisa e D esenvolvimento).

\section{REFERÊNCIAS}

1. Kinlen L. Evidence for an infective cause of childhood leukaemia: comparison of aScottish new town with nuclear reprocessing sites in Britain. Lancet. 1988 D ec;2(8624):1323-7.

2. LittleJ. Epidemiology of childhood cancer. Lyon: IARC; 1999. (Scientific Publications; no.149). p. 206-41.

3. G reaves $M$. Science, medicineand thefuture: childhood leukaemia. BM J. 2002 Feb;324:283-7.

4. Kinlen LJ, Petridou E. Childhood leukemiaand rural population movements: Greece, Italy, and other countries. Cancer C auses Control. 1995 Sep;6(5):445-50.

5. Zago M A; Falcão RP; Pasquini R, editores. H ematologia: fundamentoseprática. São Paulo: Atheneu; 2001. p. 988.

6. Patrick CC. Infectionsin immunocompromised infants and 
children. N ew York: Churchill Livingstone; 1992. p. 681-90.

7. ScottLA;StoneM S. V iral exanthems. D ermatol O nlineJ. 9(3).

8. ValeraET, Cipolotti R, BernardesJ E, PacagnellaRC, Lima $D M$, Tone LG, et al. Transient pancytopenia induced by parvovirus B19 in a child with hereditary spherocytosis. J Pediatr. 2000;76(4):323-6.

9. Oliveira $S A, C$ amacho $L A B$, Pereira $A C M$, Faillace $T F$, Setúbal $S, N$ ascimento JP. Clinical and epidemiological aspects of human parvovirus B19 infection in an urban area in Brazil ( $N$ iterói city area, State of Rio deJaneiro, Brazil). M em Inst 0 swaldo C ruz. 20020 ct;97(7):965-70.

10. Petridou E, D alamaga M , M entisA, Skalkidou A, M oustaki $M, K$ arpathiosT, et al. Evidence on theinfectious etiology of childhood leukemia: therole of low herd immunity (G reece). Cancer Causes Control. 2001 Sep;12(7):645-52.

11. Kerr JR, Barah F, Cunniffe VS, Smith J, Vallely PJ, Will $A M$, et al. Association of acute parvovirus B19 infection with new onset of acutelymphoblastic and myeloblastic leukaemia. J Clin Pathol. 2003 N ov;56(11):873-5.

12. Corcoran A, M ahon BP, M CParland P, D avoren A, D oyleS. Ex vivo cytokine responses against parvovirus $B 19$ antigensin previously infected pregnant women.J M ed Virol. 2003 Jul; 70(3):475-80.

13. G rangeot-K eros L. M olecular diagnosis of viral maternofetal infections. Ann Pharm Fr. 2003 Jul;61(4):259-64.

14. GallinellaG , Zuffi E, G entilomi $G$, M anaresi $E$, Venturoli $\mathrm{S}$, Bonvicini $\mathrm{F}$, et al. Relevance of $\mathrm{B} 19$ markers in serum samples for a diagnosis of parvovirus B19-correlated diseases. J M ed Virol. 2003 Sep;71(1):135-9.
15. Bluth M H, N orowitzK B, ChiceS, Shah VN , N owakowski $M$, Josephson $A S$, et al. $D$ etection of I $g E$ anti-parvovirus $B 19$ and increased CD 23+B cells in parvovirus B19 infection: relation to Th2 cytokines. Clin Immunol. 2003 Aug;108(2):152-8.

16. Childhood severe aplastic anaemia and parvovirus infection are linked [editorial]. J Clin Pathol. 2003 $\mathrm{M}$ ar;56(3):204.

17. Pizzo PA, Poplack D G editors. Principles and practices of pediatric oncology. 3rd ed. Philadelphia: Lippincott-Raven Publishers; 1997.

18. Corcoran A, D oyleS, Waldron D, N icholson A, M ahon BP. Impaired gamma interferon responsesagainst parvovirus B 19 by recently infected children. J Virol. 2000 $\mathrm{N}$ ov;74(21):9903-10.

19. Kaptan K, Beyan C, U ral AU, Ustun C, Cetin T, Avcu F, et al. Succesful treatment of severe aplastica anemia associates with human parvovirus B19 and Epstein-Barr virus in a healthy subject with allo-BM T. Am J Hematol. 2001 Aug;67(4):252-5.

20. Leray H , Canaud B, C ristol JP, Jonquet O, D apres G, Ortiz JP, et al. Parvovirus B19 infection revealed by acuterenal insufficiency. N ephrologie. 1992;13(3):123-5.

21. Angulo Barreras M P, Fernandez LopezA, Perez de Saracho Taramona M , Labayru Etxeberria M , Pocheville Guruzeta I, Gutierrez Villamayor C, et al. ParvovirusB19 asinfectious agent in infants. An Esp Pediatr. 1997 D ec;47(6):575-8.

22. O hio company wins $\mathrm{NIH}$ contract to manufactureparvovirus vaccine[editorial]. H eart D isW kly. $2003 \mathrm{~N}$ ov 9. 